\title{
Uncovering Family Experiences with Head Lice: The Difficulties of Eradication
}

\author{
Julie C. Parison ${ }^{*}$, Richard Speare and Deon V. Canyon
}

Anton Breinl Centre for Public Health \& Tropical Medicine, James Cook University, Australia

\begin{abstract}
Head lice (Pediculus humanus capitis) are not a significant public health concern but elicit great alarm among parents. The investigators host information websites through which they field several hundred queries annually. This study investigated the experience of those treating head lice infections focusing on control difficulties. A short web-based questionnaire (available August, 2006 and February, 2007) yielded two hundred and ninety-four eligible responses which were analysed using grounded theory analysis processes. The mainly female (91.1\%), working (76.9\%), respondents from Australia, U.S.A., Canada and UK identified constraints for effective treatment that encompass technological, biological and social issues. Product concerns, treating children and blaming others for re-infection were among the main themes. Available treatment technologies are incompatible with the lifestyles of families in developed market economies. The treatment methodology, nit comb and topically applied liquid, is several thousand years old. Future research and development efforts need to account for the social constraints experienced by lay consumers.
\end{abstract}

\section{INTRODUCTION}

The strong emotional reactions about head lice infections from the lay public contrast with the medical view where pediculosis is considered a nuisance infection with little public health significance [1]. The last global review of head lice prevalence, encompassing 1985-1997, identified a trend of increasing global prevalence [2]. Annual infections number in the hundreds of millions with up to 12 million primary school children treated in the United States of America [3]. The education departments in Australia and the United Kingdom still maintain policy for managing head lice [411].

The main foci of investigation about head lice (Pediculus humanus capitis) to date have been the biological and treatment aspects [12-14]. A search of seven major databases (keywords: head lice control family; PubMed, Ingenta Connect, Sage Online, CINAHL, Journals @ Ovid, ProQuest and Blackwell Synergy) yielded over 1400 citations which overwhelmingly encompassed biological and treatment research, with a small number of studies involving school nurse, teacher or parent perceptions, knowledge and experience of the insect [15-18]. Public health researchers have only just begun inquiry into the social context of head lice treatment, which includes parents experience [18].

Counahan et al. [18] tested the knowledge of Australian parents about head lice, from sites in North Queensland and Victoria, to identify their capacity to effectively treat the insect. Just $7.1 \%$ of parents answered all ten true or false knowledge statements correctly. Most other respondents were fifty percent correct $(63.6 \%, 821 / 1265)$. The overall findings suggested parents were overconfident in their capacity to treat. Over three-quarters of the study group spent under $\$ 50$ annually. More than $\$ 150$ annual expenditure was

*Address correspondence to this author at the Anton Breinl Centre for Public Health \& Tropical Medicine, James Cook University, Australia; Tel: +61 74781 5692; Fax: +61 74781 5254; E-mail: Julie.Parison@jcu.edu.au estimated by less than five percent of parents. Socioeconomic status data was not collected so there was no context to assess the impact of this expenditure upon these families.

The lay public, including family members such as parents, play the core health care role in a society's health care system through their normal health maintenance activities and the identification of symptoms, action for treatment, and at home care of the sick [19]. This lay public have continually sought information from the head lice information websites which Speare and Canyon have hosted for over ten years $[20,21]$. Each year there are approximately 400 inquiries from parents and carers. Treatment and eradication are their main concerns. Anecdotal information from the website queries indicated that there is a significant social impact upon those attempting to manage head lice that needed investigation. Given the dearth of research, this study sought to identify the individual, family and social issues of concern. In particular, we asked "What do you find makes controlling head lice difficult?". The results are the focus of this paper.

\section{METHODS}

A short semi-structured anonymous questionnaire was developed and made publicly accessible via the information websites $[20,21]$ on a dedicated web page (http://www.jcu. edu.au/school/sphtm/survey/HL/). Ethical approval was granted by the Human Research Ethics Committee at James Cook University (H2416). Data was collected from the questionnaire from 21 August, 2006 to 2 February, 2007. During this period over 535 responses were received. The first 332 responses were analysed for this study. The sampling strategy represents a combination of criterion based and convenience approaches [22]. The targeted participants were those who had direct experience coping with a head lice infection and were visitors to the information websites. Respondents were informed of their ethical rights and protections in a preamble before accessing the questionnaire. The questionnaire contained eight questions: four demographic (age, gender, country of residence and employment status) and four open-ended questions inquiring what respondents hoped to 
find at the website, their feelings about the head lice discovery, the difficulties they have controlling head lice and a general question about other head lice experience difficulties. For age, respondents were asked to select an age range category (Table 1). It was expected that the survey would take 5 -10 minutes to complete.

Table 1. Demographic Characteristics of Respondents

\begin{tabular}{|c|c|c|c|c|}
\hline Characteristics & Female $\mathbf{n}$ & $\%$ & Male $\mathbf{n}$ & $\%$ \\
\hline Age (years) $(n=294)$ & $(n=268)$ & 91.15 & $(n=26)$ & 8.85 \\
\hline $18-24$ & 6 & 2.0 & 1 & 0.3 \\
\hline $25-34$ & 76 & 25.8 & 3 & 1.0 \\
\hline $35-44$ & 144 & 49.0 & 12 & 4.1 \\
\hline $45-54$ & 34 & 11.6 & 6 & 2.0 \\
\hline $55-64$ & 7 & 2.4 & 3 & 1.0 \\
\hline 65 and over & 0 & 0.0 & 1 & 0.3 \\
\hline Not stated & 1 & 0.3 & 0 & 0.0 \\
\hline \multicolumn{5}{|c|}{ Country of Residence $(n=294)$} \\
\hline Australia & 165 & 56.1 & 14 & 4.8 \\
\hline $\begin{array}{l}\text { United States of } \\
\text { America }\end{array}$ & 60 & 20.4 & 6 & 2.0 \\
\hline Canada & 21 & 7.1 & 1 & 0.3 \\
\hline United Kingdom & 13 & 4.4 & 3 & 1.0 \\
\hline Others $^{\text {a }}$ & 7 & 2.3 & 2 & 0.7 \\
\hline Unknown & 2 & 0.7 & 0 & 0.00 \\
\hline \multicolumn{5}{|c|}{ Employment status $(n=294)$} \\
\hline Full-time & 107 & 36.4 & 18 & 6.1 \\
\hline Part-time & 97 & 33.0 & 4 & 1.4 \\
\hline $\begin{array}{l}\text { Not in paid } \\
\text { employment }\end{array}$ & 64 & 21.8 & 4 & 1.4 \\
\hline
\end{tabular}

Responses to the questionnaire were delivered electronically from the web page by email to the authors. Internet security was preserved via an encryption technology, secure server line (SSL) (Sun ONE Web Server 6.1) [23, 24].

Our selection criteria resulted in 38 questionnaires being excluded: twenty four due to respondents being under 18 years, 10 due to repeated submission and 4 due to incomplete responses. The net, eligible questionnaires for analysis were $n=294$.

Thematic saturation was reached after the first two hundred responses; but since this was an exploratory qualitative study, analysis was continued to confirm the findings and ensure the trustworthiness of the data [25]. Thematic saturation was further confirmed with almost one hundred more responses [26].

The responses to each thematic question were analysed for salient themes using the coding techniques of grounded theory analysis [25, 26]. Qualitative research software supported the analysis of the data [27]. A case by case analysis of responses identified key themes and sub-themes relevant to question issues. Categories were refined by a review of each category's content. Axial coding was performed and the essential elements were identified; they encompassed the causal conditions, the context, intervening conditions, action and interactional strategies and consequences [26]. The logic of the resulting categories was confirmed by RS \& DC based upon their substantial experience with parent queries via the website. This paper deals only with responses to the question "What do you find makes controlling head lice difficult?"

\section{RESULTS}

\section{Demographics}

The majority of respondents were women (90.9\%) aged 35-44 (53.2\%), working full-time (43.0 \%), part-time (34.2\%) and residents of Australia (60.7\%). The majority of female respondents were in paid employment (76.0\%). The majority of respondents (79.0\%) were from English speaking developed market economies (Table $\mathbf{1}$ ).

\section{Difficulties Controlling Head Lice: The Eradication of Head Lice}

We asked "What do you find makes controlling head lice difficult?”. This open-ended question enabled respondents free range to identify what was relevant for them. The respondents overall included a range of persons: parents, grandparents, guardians and infected or concerned others. Where descriptive responses were volunteered these involved nuclear and extended family relationships. In this set of data, therefore, the key emergent social domains involved family and school issues.

\section{Causal Conditions}

There were social-environmental causes for contracting head lice. Parents identified the school or day care centre as the site of infection. Children play and learn together in quite close proximity to friends and classmates. Children bring home the head lice and can transfer the insects to other family members with whom they also engage in close contact. Close family interaction can create a cycle of reinfection among family members. Equally, re-infection can derive from school sources.

\section{The Contexts}

The origin of infection was predominantly via school in this data derived from eleven countries. Sources also included other sites where children play together: the family home, day care, child care centres, play groups and after school care. A school bus servicing several schools in an area and an acute behavioural hospital were also mentioned.

\section{Action and Interaction}

Upon discovery of head lice, respondents were compelled to search for a solution and carry out the initial treatment as soon as possible. Effective treatments were stated to be the right "chemical", "natural" or home remedy. The definition of effective treatment, from the respondents perspective, was a process that eradicated both head lice adults/nymphs and eggs. If effective treatment did not occur, then further information was sought from friends and relatives, pharmacists or the internet. This led all of these respondents to the Speare and Canyon's head lice information 
websites seeking effective eradication information. For some who had never encountered head lice before, searching the internet was their first action.

Ongoing monitoring of their children and their own heads occurred using the conditioner and combing technique. Others adopted the seven or ten day cycle according to treatment solution instructions or had to try several treatment chemicals to find an effective treatment. Initially some parents treated all their family members' heads, and cleaned their whole house and laundered all linen that had contact. Disposing of infected pillows and buying new ones was an additional strategy adopted by a small number. Upon learning about the more appropriate cleaning methods from the website, respondents were relieved.

Some parents notified their children's school about the infection, but received no response or a limited response.

\section{Intervening Conditions}

Intervening conditions represent those "conditions [that] act to either facilitate or constrain the action or interactional strategies taken within a specific context” [26]. As we asked about control difficulties, respondents reported the negative intervening conditions. The intervening conditions here are technological, biological and social constraints. For an overview refer to Fig. (1).

\section{Technological Intervening Conditions - Treatment Diffi- culties}

Many respondents found commercial products and methods ineffective and difficult and had safety concerns (Table $\mathbf{2}$ and Fig. (2)).

Some parents were worried about using pesticides repeatedly on their children and explored other treatments perceived to be safer or "natural". Trying several products was common. The issue of insect resistance to products was understood by some. Some found the nit comb difficult to use, the method cumbersome, complete coverage of solution onto hair difficult, and moving the comb through the hair caused pain.

Table 2. The Difficulties of Carrying Out Head Lice Treatments: Technological Constraints

\begin{tabular}{|c|c|c|}
\hline Theme $(n=294)$ & $\mathbf{n}$ & $\%$ \\
\hline \multicolumn{3}{|l|}{ The treatment technology } \\
\hline Finding an effective treatment product & 30 & 10.2 \\
\hline Difficulty of chosen treatment method & 25 & 8.5 \\
\hline Ineffective commercial treatments & 17 & 5.8 \\
\hline Concern about chemicals and sensitivity to them & 16 & 5.4 \\
\hline Finding safe natural treatment & 6 & 2.0 \\
\hline Finding an effective treatment method & 5 & 1.7 \\
\hline Distaste for the treatment process & 4 & 1.4 \\
\hline Using the right comb & 2 & 0.7 \\
\hline Distaste for treatment product & 1 & 0.3 \\
\hline \multicolumn{3}{|l|}{ Treatment techniques } \\
\hline Hair type & 35 & 11.9 \\
\hline Removing all the eggs & 35 & 11.9 \\
\hline Self treatment & 7 & 2.3 \\
\hline Inexperience with treatment & 6 & 2.0 \\
\hline
\end{tabular}

Treatment was further hampered by the type of hair being treated. Thick, long, curly hair was difficult to apply solution onto and manoeuvre the comb through. Current techniques do not appear to support the removal of all eggs; a goal of respondents. Self-treatment can be difficult and a lack of experience further hampers successful treatment. Embarrassment can deter respondents asking others for help

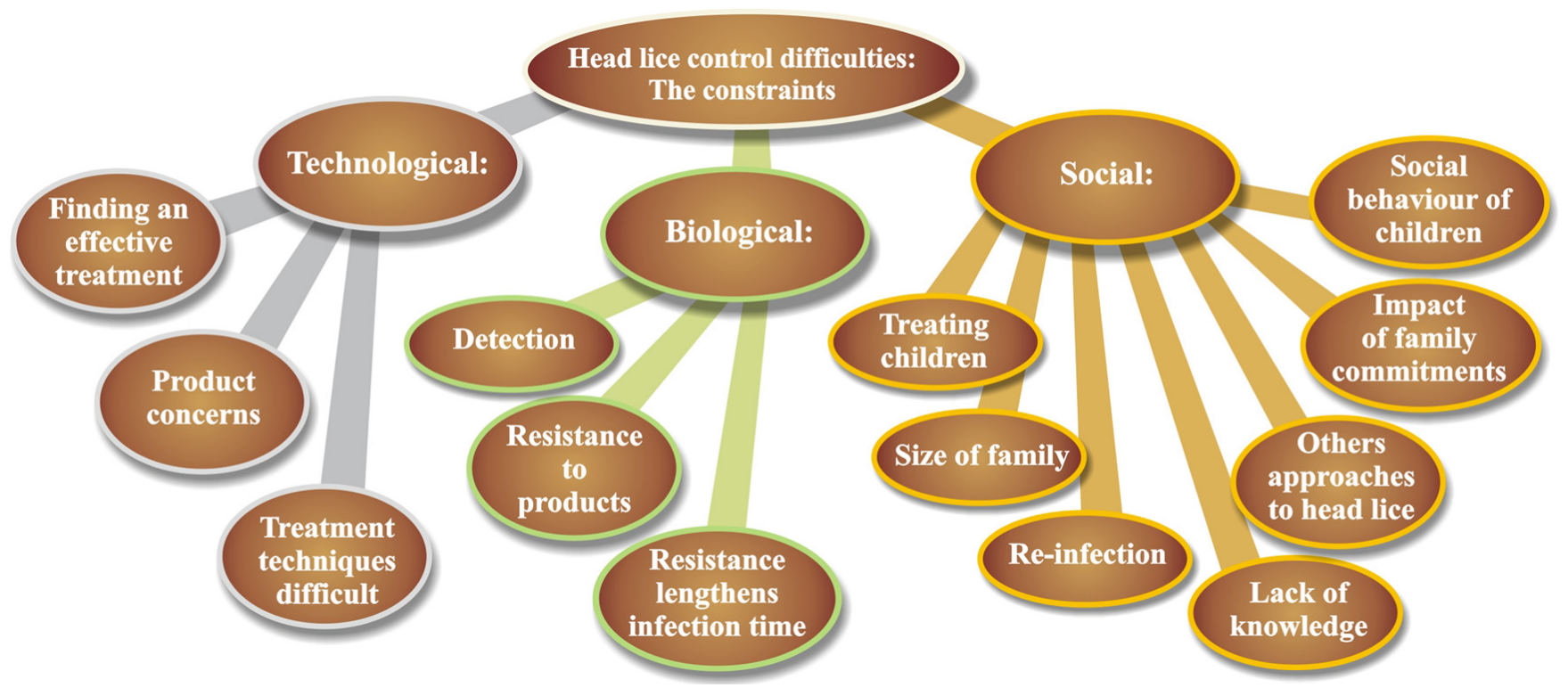

Fig. (1). Head lice control difficulties: the lay perspective. 
Technological Constraints:

Finding effective treatment method:

... I have spent so much money on the electric combs the big long ones and all these different products and we still have lice. SQ049.

The fact that there is not a product that can kill them in one go, eggs as well. SQ077.

Difficulty of treatment method:

From a practical standpoint, the combing approach, while apparently successful in our case (9 year-old son) seems in principle impossible to carry out adequately. Can you really be sure you've combed out EVERY hair on a child's head? SQ137.

... applying product to very long dry hair [is problematic] as it is difficult to know whether you are using enough product and very hard to saturate hair all the way to the ends! SQ 151.

Hair type:

Long hair, .. is definitely harder to patrol. SQ244.

\section{Biological Constraints:}

Resistance to products:

I can't believe how tenacious the little critters are. SQ274.

They are frustrating and immune to a lot of the products. Some that may have worked very well last year don't necessarily work now. SQ191.

We cannot get rid of them. We have tried two treatments of Nix, 3 treatments of Ovide and are currently on Bactrim. After the 3 Ovide treatments, I am now trying Dr. Perlman's NuVo treatment. I pray it works. We are going on 6 weeks. ... I have done everything that all the research says to do, nothing has worked. HELP! SQ203.

Difficulty of detection:

This was the first time I had ever seen eggs and live lice before and they were not what I was expecting. I thought they would be bigger and a lot easier to spot. It turns out that my son's hair is the same colour as the 2 adults I found. SQ063.

I can't see the damn things! I had to get a magnifying mirror. ... It's like fighting an invisible army. SQ236.

\section{Social Constraints:}

\section{Treating children:}

... One child is great with the treatment (5yo), but my 2yo screams bloody murder and goes into full hysterics when treated, needless to say he now sports a shaved head!!!! SQ 121.

Keeping my three year old's head still enough to use a nit comb - there is no way I was able to do the thorough combing described as essential by most treatment methods. He was screaming and thrashing around before I was even 20\% done. SQ173.

Size of the family:

I have 6 children, I work full time and my husband is no help so it takes a lot of time and money for me to get rid of lice. SQ 306.

I have 6 kids here and I have to clean all their heads. It's a pain in the butt, but I want them to be able to go to school and not bring them to school with them. SQ 232.

Re-infection:

I treated my kids and [the] treatment worked and then I found full grown lice two days later. I have learnt to be a proficient lice / egg finder but they seem to be becoming reinfected somewhere ... SQ061.

Getting rid of them completely is next to impossible. We had the son and daughter clear for 10 days (I had a number one haircut after nuking them) but they kept coming back, so one of them was getting them from somewhere. Probably [the] daughter from school. SQ299.

The fact that there are always outbreaks at school - at least 2-3 times per term. SQ177.

... Reinfection from school [is a control difficulty], lice are treated using the 14 day treatment, all seem to have gone and then there is another outbreak in the class and we start the whole procedure again. SQ324.

Other parents approach to head lice:

[The difficulty is] Other parents not being so vigilant to check their kids' hair and thus spreading the lice further. I know a number of parents that say they will wait till the weekend to do the treatment!!!!!. SQ298.

I was so annoyed because I have been treating my children for 2 years, while the children associate with other children at school who are known to have them, but the parents are not doing anything to eradicate them. SQ146.

Variable school action:

Often the school [in Australia] makes all the class check daily and treat if evidence found. But after treatment, I often still find eggs for a few days...

SQ225.

I have 4 young girls with long hair and myself with long hair, I follow the guidelines (and beyond) of getting rid of them and they go to school and they get them again. I have been getting them for about 2 years and the school [in Australia] will not do anything about it. SQ098.

Lack of concern for them (nits) at school. We used to get a note if one of the kids in class had nits so we would check. Now we hear nothing about it so I can only assume schools do not have a nit policy. SQ299, Australian father.

Fig. (2). Parent difficulties in their own words: technological, biological and social constraints.

thereby limiting their access to personal support for treatment.

\section{Biological Intervening Conditions}

Respondents believed that head lice are resistant to certain insecticidal products $(\mathrm{n}=38,12.9 \%)$ and encountering this resistance was thought to lengthen the period of infection ( $\mathrm{n}=$ $15,5.1 \%)$. The insect is difficult to detect on others and oneself and this complicates location and removal (Table $\mathbf{3}$ ).

The origin of infection can be a mystery to many for infections are not initially marked by itching or other sensations and can go undetected for some time. 
Table 3. The Difficulties of the Detection of Head Lice: Biological Constraints

\begin{tabular}{|c|c|c|}
\hline Theme $(\boldsymbol{n}=\mathbf{2 9 4})$ & $\mathbf{n}$ & $\mathbf{\%}$ \\
\hline \hline Difficulty of detection & 19 & 6.5 \\
\hline Finding all the eggs and lice & 11 & 3.7 \\
\hline Lack of knowledge and experience in finding head lice & 10 & 3.4 \\
\hline Origin of infestation a mystery & 6 & 2.0 \\
\hline Asymptomatic presence of life & 6 & 2.0 \\
\hline Self detection & 3 & 1.0 \\
\hline
\end{tabular}

\section{Social Intervening Conditions}

A whole range of social context conditions exacerbate the head lice control difficulties for parents. The subjects of most treatment are children.

\section{Treating Children}

Treating children has its own set of difficulties (Table 4 and Fig. (2)). Long hair was the most recognised problem and added to treatment time and difficulty. This was exacerbated by thickness, curliness, and hair structure.

Table 4. Social Constraints: Treating Children and Lack of Knowledge

\begin{tabular}{|c|c|c|}
\hline Theme $(n=294)$ & $\mathbf{n}$ & $\%$ \\
\hline \multicolumn{3}{|l|}{ The difficulties of treating children } \\
\hline Length and type of hair & 39 & 13.2 \\
\hline Social space and school activity behaviour & 39 & 13.2 \\
\hline Children unable to sit still & 28 & 9.5 \\
\hline Children intolerant of lice combing \& treatment & 27 & 9.2 \\
\hline Age of children & 18 & 6.1 \\
\hline Size of family & 14 & 4.8 \\
\hline Work commitments and family living arrangements & 12 & 4.1 \\
\hline \multicolumn{3}{|l|}{ Lack of knowledge about head lice } \\
\hline Respondents admitting a lack of knowledge & 12 & 4.1 \\
\hline “Inaccurate” information & 7 & 2.4 \\
\hline Conflicting information & 5 & 1.7 \\
\hline Pharmacy misinformation & 4 & 1.4 \\
\hline Lack of knowledge in general population & 4 & 1.4 \\
\hline Perception that parents have a lack of knowledge & 3 & 1.0 \\
\hline Lack of scientific technological advancement & 2 & 0.7 \\
\hline Lack of unspecified knowledge & 1 & 0.3 \\
\hline
\end{tabular}

Responding parents encouraged preventative behaviour with their children, particularly younger ones, with little effect. Children cannot be monitored all the time at school and home. Parents perceive that interaction between children at school and home supports the transmission of the insects. Children are mobile, have their heads together when playing and studying, and sometimes do not keep their hair tied back. Another parental concern was that children share items such as headbands, brushes and hats.

Children dislike sitting still during treatment stages including the combing and the application of chemicals. Wriggly, impatient, resistant, distressed, or thrashing and screaming children make it difficult to thoroughly check their head, apply the treatment and move the comb through the hair thoroughly. Children younger than 3 years were the most difficult to treat.

The number of children in a family increases the treatment time. Of 13 respondents who stated the numbers of people to treat in their family, the range was 2-6 persons with the mean being 4.2. Even where there is just one child, it is a burden because the cleaning work must be done after work hours, usually in the evening.

Work commitments and family living arrangements make it difficult for some parents to find time to keep up a treatment regime. Paid work commitments for full-time and part-time working mothers and the school schedule limit available time with children. Mothers not in paid employment with a busy schedule find it difficult. When a parent works outside school hours or where both parents work or have split care arrangements, such as separated or divorced parents, this further strains the availability of treatment time and the maintenance of an effective treatment regime.

\section{Re-Infection}

Significantly, after doing all the work to treat their children, and in some cases treat themselves too, many parents expected re-infection or found their child was re-infected when he or she returned to school or day care $(n=73$; 24.8\%; Fig. (3)). This was the second most stated concern in the whole study.

\section{Perceived Approaches to Head Lice by Parents and Others}

There is the perception that there are always parents or guardians, who do not treat their children $(n=37 ; 12.6 \%)$ or that there is ineffective treatment being conducted by others $(\mathrm{n}=30 ; 10.2 \%)$. Respondents are not happy about this lack of diligence using phrases like other parents "not bothering" to treat their children. Ineffective treatment strategies mean re-infection is likely and this poses a barrier to effective eradication. Identified reasons for limited or non-treatment were economic stress, time, ignorance or laziness.

\section{Variable School Action}

A range of monitoring and treatment approaches by schools were reported: active effective school approaches (treatment programs, school monitoring), limited ineffective intervention and prevention strategies (recommendations and notifications to parents, school monitoring) or no action (notifications ceased, attendance policy lacking, no checking allowed by government) ( $\mathrm{n}=22 ; 7.5 \%)$.

\section{Lack of Knowledge About Head Lice}

A lack of knowledge about head lice matters prevents the implementation of effective treatment processes. Knowledge limitations were identified by respondents within themselves, in the information provided to them by others, with other parents, and with the scientific community (Table 4). 
Inaccurate or conflicting information was encountered in their search, including from pharmacy staff. A couple of respondents felt that a vaccination or research on alternative treatments should exist given the state of contemporary human technological and scientific advances.

\section{Consequences}

\section{Social Consequences - The Impact Upon the Female Par- ent}

The female parent is, in the majority of cases, the head lice treatment manager. The resources for treatment centre upon and depend on her activity (Table 5 and Fig. (3)).

Table 5. Consequences for Family Carer's Treatment of Head Lice

\begin{tabular}{|c|c|c|}
\hline Themes $(\boldsymbol{n}=\mathbf{2 9 4})$ & $\mathbf{n}$ & $\mathbf{\%}$ \\
\hline \hline Time required to treat & 77 & 26.2 \\
\hline Money required to treat & 31 & 10.5 \\
\hline Amount of cleaning work needed and carried out & 28 & 9.5 \\
\hline Energy required & 14 & 4.8 \\
\hline
\end{tabular}

\section{Time}

The time to treat one or more cases was the most stated issue in the whole study. Working mothers have little spare time and when families have several children the head treatment time is multiplied. The individual treatment time according to hair type and the cycle of treatment required to monitor each case add to the overall time required. The time factor was an issue for relatively equivalent numbers of fulltime, part-time workers and respondents not in paid em- ployment $(\mathrm{n}=28,22.4 \% ; \mathrm{n}=26,25.7 \%$; and $\mathrm{n}=23,33.8 \%$ respectively). Two males identified time as an issue, one was a father treating his child. The infection duration stated by a few ranged between four weeks to almost three years ( $\mathrm{n}=$ 15).

Head treatment and house cleaning information was volunteered by mainly women. Although males responded to the survey $(8.8 \%)$, only two stated that they were treating heads (a full-time worker and one not in paid employment). No males contributed to the responses about the energy, the work of the treatment and cleaning required or the length of the infection time.

\section{The Expense}

The expense of commercial treatment products was a strain for families ( $\mathrm{n}=31 ; 10.5 \%)$. An Australian teacher stated "Often families are unable to afford the treatment on a regular basis" (SQ070). The family cost escalates with the process of experimentation to find an effective treatment, the length of hair, the amount of treatment liquid required for each application, and the need for ongoing periodic treatment to deal with re-infection. This cost is then multiplied by the number of infected people in the family.

Expense was equally relevant for full-time $(n=12,9.6 \%$ of all full-time workers), part-time workers ( $\mathrm{n}=11,10.9 \%$ of all part-time workers) and those not in paid employment ( $\mathrm{n}=8,11.8 \%$ of all not employed). Household family income was not collected so further analysis was not possible.

\section{Treatment and House Cleaning Work}

Many, before reading the information websites, had misconceptions about who needed treatment and what needed cleaning $(n=28)$. Several parents treated all family members, cleaned the whole house, and laundered all affected

Time:

Frustration at having found head lice and just another thing that has to be done in an already busy schedule. SQ 324, part-time working mother.

Time....it takes so much time to control it and between work and school, not much time to spend on the head each night. SQ181, full-time working mother.

The time, I have only just got my boys to bed at $10.30 \mathrm{pm}$, it took about 2.5 hours to deal with them. SQ279, full-time working mother.

The expense:

... Finding the right product- they are insanely expensive, and for example, the one I just used hasn't worked so, as I have just learnt about resistance to product, I will have to spend more money on another active ingredient/product, ... SQ159.

The pesticides are dangerous and VERY costly. SQ166.

I was annoyed that I had to start the process of getting rid of them. Especially as we were short of cash at the time and the treatments are all pretty expensive. SQ270.

I am sick of spending so much money on products and nothing works. SQ382.

Cleaning needed and conducted:

...You have to go back and find everything that you touched up to two days before...for instance your bedding and stuffed animals etc. We had to treat our entire family when our youngest child had head lice ... [With] 3 kids and [a] 3 storey home you have to be sure to wash EVERYTHING it's hard to keep up. SQ046, female parent, not in paid employment, U.S.A.

It's just all the combing and combing. Then I wash hair and when I wash the towels, I find dead lice in the drier. I just feel like I can't get rid of them. Just feeling like I constantly need to clean. And I feel like I can't get rid of them all. SQ193, female parent, part-time employed, U.S.A.

Energy required:

Hard work and devoting time combing hair hot washing of sheets and pillow cases when don't have much time to spare. SQ198, female, part-time worker, Australian.

So many people in the house and the teenagers don't want to do the daily care of looking for lice. I'm the one suffering ....my husband doesn't have them so his attitude is much different than mine.

SQ246, female, not in paid employment, U.S.A.

Fig. (3). Consequences in parents own words. 
linen. Some parents discarded pillows and purchased new manchester. They saw the cycle of cleaning as a continual process required until the infection was cleared. The cleaning issue was identified by equivalent numbers of full-time $(\mathrm{n}=$ $10 / 125=8.0 \%)$, part-time workers $(n=8 / 101=7.9 \%)$ and respondents not in paid employment $(n=10 / 68=14.7 \%)$.

Given the cleaning chores many respondents thought they had to do, the energy and work required by the female parent, to keep up the treatment and cleaning regime, for people, the house and the laundry, was a burden $(n=14$, $4.8 \%$ ). This energy and work was an issue for all employment status groups: full-time $(n=5 / 125=4.0 \%)$, part-time $(\mathrm{n}=3 / 101=3.0 \%)$ and respondents not in paid employment $(\mathrm{n}=6 / 68=8.8 \%)$.

\section{DISCUSSION}

This internet questionnaire enabled anonymity which resulted in frank disclosure from respondents. The responses indicated a consistency of parent experience across the countries surveyed, in particular, Australia, the United States, Canada and the United Kingdom. We did not reach any persons who think treating head lice is not a problem. The questionnaire limited our capacity to enquire into issues with follow up queries in the style of an in-depth interview [25]. However, the general themes identified allowed the development of an axial coding framework ranging across the different action dimensions of respondent experiences. These findings provide a useful beginning towards understanding lay experience with head lice.

We asked what control difficulties respondents had with head lice. They replied from a different frame of reference. They wanted to eradicate the insects, not just control them. In the infectious disease context, "control" means bringing the incidence or impact of a pathogen to an "acceptable" level, whereas eradication means removing the pathogen completely from the host. Health professionals need to be aware that for head lice, the client's goal is much more demanding than theirs. Hence, miscommunication can arise, resulting in frustration with responses from health professionals. Since parents perceive head lice as a significant health problem and desire assistance from health authorities [18], health authorities must accept a responsible role in their control. This finding suggests that negotiating a shared understanding of what can be achieved is very important. More research should be directed into determining the best strategies for doing this.

All of the activity to treat the problem is the responsibility of the mainly female parents. Most respondents ( $\mathrm{n}=$ 267; 90.8\%) were female and they were the head lice managers. This responsibility for head lice treatment is an extension of the female parenting role. These female parents even carried out the work of finding a solution through an internet search. In the division of family labour, female parents in traditional nuclear families still spend more time than their male partners conducting household work and child care even when they are in paid employment [28-33]. This study demonstrates that the gendered division of childcare and domestic cleaning work in western market economies also extends to the health care activity that is head lice treatment.

Most respondents were female parents in age ranges specific to child rearing years (25-44 years). The social issues of concern were difficulties related to treating children. The social issues described focused on the experience of families with children attending pre-school and primary school. This corresponds with the known incidence of head lice. Children are the unwitting primary transmitters of this ancient infection because of their communal interactions and lack of preventive precautions.

There is currently no single protocol for treating head lice recommended by health authorities. The elements of control promoted by health authorities are 1) use of a sensitive detection method; (the most sensitive is application of a liquid that "stuns" lice and detection by combing with a nit comb [34]; 2) killing of lice by an insecticidal compound and / or removal of these insects by use of a fine tooth comb; 3) repeat of step 2 to kill or remove insects that have emerged from eggs at a time that will not allow the newly hatched lice to reach maturity; and 4) removal of eggs by special fine toothed combs [35] or manually. Killing lice has become more difficult in developed market economies owing to the increasing prevalence of insecticide resistance [36]. The commercial response has been to develop "natural” head lice products based on herbs and essential oils [37]. Hence, eradicating head lice from a child's head is a complex task which requires a good understanding of head lice biology, a willingness to deal directly with unwanted "wildlife", complex therapeutic decision making, skills in using ancient therapeutic modalities in a modern context, and persistence and dedication to achieve a specific goal. It is in this context that our respondents made their comments on the difficulties they were experiencing.

The experience of respondents in this study corresponds to the evidence about head lice biology. Head lice are difficult to detect and eradicate $[1,14,38]$. They are complicated creatures for parents to treat without accurate knowledge or treatment experience due to their changing physical states from egg to nymph to adult $[14,38]$. Their greatly varying resistance to commercial treatment products adds considerably to treatment difficulty $[4,39]$.

The technological, biological and social difficulties cited by respondents illustrate the inappropriateness of available treatment technologies due to the safety concerns, the difficulties when treating children and the limited time available to do so. Given these difficulties there is a large potential market for effective, safe, quick, painless, affordable head lice treatments beyond what is currently available. The current modalities of comb and solution represent a technique that has been employed for at least ten thousand years of human head lice infection history [40]. Parents have recognised the convenience of pet flea treatments, such as insect growth regulators, which prompted an Australian state health department warning [41]. Research and development of new treatment technology needs to account for the impact of the constraining social factors identified by respondents in this study.

The social and ecological environment makes treatment difficult for parents as well. Families, large or small, can maintain a cycle of reinfection within the household. School community transmission is the other main concern and is justified by epidemiological data [12]. Treatment managers at home realised that while children were still at school, continual monitoring of their children and affected others would 
be necessary but not possible. So an inter-related social consequence is the expectation of reinfection.

An important consequence of this reinfection cycle is that respondents resent the lack of diligence on the part of other parents who send children to school untreated or poorly treated. This blaming of "other parents" taking place is not in many cases based on evidence we can substantiate within their replies. The detection of head lice, in the egg stage in particular, is difficult as noted earlier [14] and it is hard to determine if a treatment has been effective. Where blaming occurs, four possibilities exist: reinfection at school or elsewhere, non-treatment, ineffective treatment, and, or resistance. Measures to increase understanding and knowledge within school communities need to exist to help avoid an unhealthy culture of blame and instead foster a positive environment and collaborative approach to treatment within and beyond the school setting. To that end we support the stance of many health professional associations and researchers in discouraging the implementation of "no nit" attendance policies for schools given that the social effects, including stigma, outweigh any public health benefit of head lice control [42-44, 36, 45].

A range of school interventions were mentioned by respondents but they provided an incomplete picture of the school's role in head lice eradication. The scope and implementation of head lice programs needs to be documented and effective school- home models for head lice management need to be publicised.

The issue of a lack of knowledge requires systematic exploration. This theme encompassed some of the individual, professional and social transactions of respondents, but the range of experiences reported were limited. State and national education and health authorities supply parents with information [4-8, 10, 11, 46], but this may be insufficient for parent needs. Counahan et al. [18] found that though the majority of their respondents had received advice about head lice (in the Australian states of Victoria 82.2\% and North Queensland 78.9\%) a majority of these wanted further information (Victoria 50.0\%, North Queensland 67.4\%). Since all of our respondents visited the information websites, by implication they were all seeking more information about head lice. The type of information sought by respondents in this study, which will be reported later, included insect biology, treatment and prevention facts. Access to sufficient, accurate information is a basic requirement for the efficient control of head lice.

Other barriers for parents to treat head lice need to be understood. This study raised several questions around this issue. Are the strains upon the female parent with time, energy, and cost the reason some parents do not treat at all? Does stigma prevent some parents from engaging with their child's school?

In addition to effective school head lice management programs, consistently applied school policy is important. It appears that effective treatment information is not reaching the respondents in this study and that the school policies in place, in some instances, have lapsed in their application. The Ottawa Health Promotion Charter framework can provide inspiration for schools, education departments and parent associations to develop a holistic approach for manage- ment [47]. The framework involves building healthy public policy, creating supportive environments, strengthening community action, developing personal skills and reorienting health services. Within this framework the health promotion actors, and this can include all stakeholders here, adopt advocating, enabling and mediation roles to develop programs. Comparing this framework with these study findings, what appears to be lacking overall is a strong community presence in the school setting and at home. This would enable individuals to develop social support networks that would give them the skills to be more effective head lice managers. Programs that employ these principles, and which are evaluated as being effective, need to be publicised. There is a role for building healthy public policy as well. Where policy is lacking or limited, a negotiated standard for head lice management between school personnel and parent associations should be developed. And finally, in a broader interpretation of reorienting health services, research and development organisations should work towards developing treatment technologies more suited to contemporary forms of social organisation in western market economies to resolve the gap between the current treatment capacity and consumer goals for head lice eradication.

\section{CONCLUSIONS}

This study represents the beginning of research into the socio-behavioural dimensions of dealing with pediculosis. It also represents the first time the public have had the opportunity to express their problems within the context of a research study devoted to their perspective. The data clearly indicates available solution products are incompatible with contemporary social organisation in western market economies particularly where female parents are working. These findings should inform future product development and would certainly provide a basis for R \& D company product development and marketing research.

\section{REFERENCES}

[1] Counahan M. Scratching for Answers? Public health aspects of head lice control. [PhD dissertation]. Townsville: James Cook University, Australia; 2006.

[2] Gratz NG. Human lice. Their prevalence, control and resistance to insecticides. A review: 1985-1997 [document on the Internet]. Geneva: World Health Organization, Division of Control of Tropical Diseases (CDT), WHO Pesticide Evaluation Scheme (WHOPES), WHO/CTD/WHOPES/97.8; 1997 [cited 2007 Nov 22]. Available from: http://www.who.int/whopes/resources/en/.

[3] Mumcuoglu KY, Meinking TA, Burkhart CN, Burkhart CG. Head louse infestations: the no nit policy and its consequences. Int $\mathrm{J}$ Dermatol 2006; 45: 891- 96.

[4] Department of Education, Victoria. Head Lice Management Tool Kit [document on the Internet]. Melbourne: Victorian Department of Education; 2002 [updated 2007, July 8; cited 2007 Oct 4]. Available from: http://www.sofweb.vic.edu.au/wellbeing/headlice/.

[5] Department of Education and Children's Services. Parent Information Letter [document on the Internet]. Adelaide: Government of South Australia; 2006 [updated 2006, December, 20; cited 2007 October 4]. Available from: http://www.decs.sa.gov.au/speced2/ files/pages/chess/hsp/Pathways/SAMPLE_school_headlice_man.doc.

[6] Department of Education, Employment and Training. Head Lice Infestation (Pediculosis), Health Issues, HI-03.1.1, School Policy Handbook [document on the Internet]. Darwin: Northern Territory Government; 1998 [updated 1998, January; cited 2007 October 4]. Available from: http://www.deet.nt.gov.au/corporate/policies/health_issues/hi-03.1.pdf.

[7] Department of Education \& Department of Health and Human Services. Head Lice Policy [document on the Internet]. Hobart: Tasmanian Government; 1999 [updated 2007 April 11; cited 2007 October 
4]. Available from: http://www.education.tas.gov.au/school/educators/health/headlice_in_schools/policy.

[8] Department of Health. Head Lice [document on the Internet]. Perth: Government of Western Australia; 2007 [updated 2007; cited 2007 October 4]. Available from: http://www.population. health.wa.gov.au/Communicable/headlice.cfm.

[9] NSW Health. Nitbusters: Head Lice in Schools Program [information on the Internet]. Sydney: New South Wales Government; 2007 [updated 2004 August; cited 2007 October 4]. Available from: http://www.health.nsw.gov.au/headlice/nitbusters/index.html.

[10] Queensland Education. HLS-PR-011: Control of Head Lice in Schools (version 1.0), Education Policy and Procedures Register [document on the Internet]. Brisbane: Queensland Government Education Department; 2007 [updated 2006; cited 2007 October 4]. Available from: http://education.qld.gov.au/strategic/eppr/health/ hlspr011/.

[11] Hansard (House of Commons Daily Debates). Head Lice [document on the Internet]. The United Kingdom Parliament, Session 2006-07, Oral Answers, 11 Jun 2007: Column 790W [updated 2007 June 11; cited 2007 October 4]. Available from: http://www. publictions.parliament.uk/pa/cm200607/cmhansrd/cm070611/text/70 611w0016.htm.

[12] Speare R, Buettner, PG. Head lice in pupils of a primary school in Australia and implications for control. Int J Dermatol 1999; 38: 285-290.

[13] Speare R, Thomas G, Cahill C. Head lice are not found on floors in primary school classrooms. A \& NZ J Public Health 2002; 26(3): 208-211.

[14] Burgess IF. Human Lice and their Control. Ann Rev Entomol 2004; 49: 457-481.

[15] Eckartz B, Schillat S, Greene LL. The family as client in the school setting. Nurs Diagn 1996; 7(3): 125 - 128.

[16] Price JH, Burkhart CN, Burkhart CG, Islam R. School Nurses' Perceptions of and Experiences with Head Lice. J School Health 1999; 69(4): 153-158.

[17] Kirchofer GM, Price JH, Telljohan SK. Primary grade teachers' knowledge and perceptions of head lice. J Sch Health 2001; 71(9): 448-453.

[18] Counahan ML, Andrews RM, Weld H, Walsh H, Speare R. What parents in Australia know and do about head lice. Rural and Remote Health [serial on the Internet]. 2007; [cited 2007 October 10]; 7: 687 [10 pages]. Available from: http://www.rrh.org.au.

[19] Kleinman, A. Patients and Healers in the Context of Culture. Los Angeles, CA: University of California Press, 1980.

[20] Speare R. Health Lice Information Sheet [web page on the Internet]. Anton Breinl Centre for Public Health \& Tropical Medicine, James Cook University; 2007 October 28 [cited 2007 November 19]. Available from: http://www.jcu.edu.au/school/phtm/PHTM/ hlice/hlinfo1.htm.

[21] Speare R. \& Canyon DV. DeLouse Speare \& Canyon's interactive website for the diagnosis and treatment of pediculosis [information on the Internet]. Anton Breinl Centre for Public Health \& Tropical Medicine, James Cook University; 2006 [cited 2007 November 20]. Available from: http://www.jcu.edu.au/school/sphtm/antonbreinl/centers/vcrrc/hl/DeLOUSE/index.htm.

[22] Patton MQ. Qualitative Research \& Evaluation Methods. 3rd ed. Thousand Oaks, CA: Sage, 2002.

[23] Nosek BA, Banaji MR, Greenwald AG. E-research: ethics, security, design, and control in psychological research on the Internet. J Soc Issues 2002; 58(1): 161 -176.

[24] Sun Microsystems. Sun ONE Identity Server 6.1 Administration Guide [document on the Internet]. Santa Clara, California; 2003 [updated 2003; cited 2006 May 4]. Available from: http://docs. sun.com/source/816-6773-10/sslsetup.html\#wp16512.

[25] Neuman WL. Social Research Methods Qualitative and Quantitative Approaches. $6^{\text {th }}$ ed. Boston: Pearson Education, 2006.

[26] Strauss A, Corbin J. Basics of Qualitative Research Grounded Theory Procedures and Techniques. London: Sage, 1990.

[27] QSR International. QSR N6 [computer software program]. Doncaster, Victoria: QSR International, 2002.
[28] Australian Bureau of Statistics. Unpaid child care: by age by sex. Census of Population and Housing in Australia [data file on the Internet]. Cat. No. 2068.0, b21; 2006 [updated 2006; cited 2007 October 10]. Available from: http://www.abs.gov.au/.

[29] Australian Bureau of Statistics. Unpaid domestic work: number of hours by age by sex. Census of Population and Housing in Australia [data file on the Internet]. Cat. No. 2068.0, b19; 2006 [updated 2006; cited on 2007 August 8]. Available from: http://www. abs.gov.au/.

[30] Office for National Statistics. The Time Use Survey 2005 [document on the Internet]. London: Office of National Statistics, United Kingdom; 2006 [ updated 2006; cited on 2007 October 9]. Available from: http://www.statistics.gov.uk/cci/article.asp?ID=1600.

[31] Geist C. The Welfare State and the Home: Regime Differences in the Domestic Division of Labour. Eur Soc Rev 2005; 21(1): 23-41.

[32] Sullivan O. The division of domestic labour: Twenty years of change? Sociology 2000; 34(3): 437-456.

[33] Baxter J. Patterns of change and stability in the division of household labour in Australia, 1986-1997. J Sociology 2002; 38(4): 399424.

[34] Ibarra J, Fry F, Clarice W, et al. Overcoming health inequalities by using the Bug Busting 'whole-school approach' to eradicate head lice. J Clin Nurs 2007; 16: 1955-1965.

[35] Speare R, Canyon DV, Cahill C, Thomas G. Comparative efficacy of two nit combs in removing head lice (Pediculus humanus var. capitis) and their eggs. Int J Dermatol 2007; 46: 1275-1278.

[36] Lebwohl M, Clark L, Levitt J. Therapy for head lice based on life cycle, resistance, and safety considerations. Pediatrics 2007; 119: 965-974.

[37] Heukelbach J, Canyon D, Speare R. The effect of natural products on head lice: In vitro tests and clinical evidence. J Pediat Inf Dis 2007; 2: 1-10.

[38] Williams LK, Reichert A, MacKenzie WR, Hightower AW, Blake PA.Lice, Nits and School Policy. Pediatrics 2001; 107(5): 10111015.

[39] Mumcuoglu KY, Hemingway J, Miller J, et al. Permethrin resistance in the head louse Pediculus capitis from Israel. Med Vet Entomology 1995; 9(4): 427-32, 447.

[40] Reed DL, Smith VS, Hammond SL, Rogers AR, Clayton DH. Genetic analysis of lice supports direct contact between modern and archaic humans [serial online]. Plos Biol 2004 [cited 2007 Sep 20]; 2(11): 1972-1983. Available from: http://biology.plos-journals. org/perlserv/?request=get-document\&doi=10.1371/journal. pbio.0020340.

[41] Queensland Health. Media Statement: Head Lice Case Triggers Pet Drug Warning [document on the Internet]. Brisbane, Queensland Health, 2007 [updated 2007 May 11; cited 2007 July 25]. Available from: http://www.health.qld.gov.au/news/docs/head_lice.pdf.

[42] Anonymous. Compromising on School for Students with Head Lice. The Education Digest 2004; 69(6): 61-63.

[43] Canadian Pediatric Society (Infectious Diseases and Immunization Committee). Head Lice Infestations: A Clinical Update. Paediatrics \& Child Health 2004 [cited 2007 Oct 2]; 9(9): 647-651. Available from: http://www.cps.ca/english/statements/ID/ID04-02.htm\#School.

[44] Frankowski BL, Weiner LB, Committee on School Health and Committee on Infectious Diseases. Head Lice. Pediatrics 2002; 110: 638-643.

[45] Roberts RJ. Head Lice. N Eng J Med 2002; 346(21): 1645-1650.

[46] Ministry of Health, British Columbia. Head Lice BC Health Files [document on the Internet]. Vancouver: Ministry of Health; 2007 [updated 2006 March; cited 2007 Sep 14]; March, Number 06. Available from: http://www.bchealthguide.org/healthfiles/index. stm.

[47] World Health Organisation. Ottawa Charter for Health Promotion [document on the Internet]. First International Conference on Health Promotion, Ottawa, 21 November; WHO/HPR/HEP/95.1, 1986 [cited 2007 Sep 13]. Available from: http://www.who. int/hpr/NPH/docs/ottawa_charter_hp.pdf. 